\title{
Hidden figures in ecology and evolution
}

To the Editor - Equity efforts consistently disregard the perspectives, contributions and accomplishments of Black women. Habitually, Black women's accomplishments are marginalized in favour of white and/ or male agendas. This societal disregard dates back to the women's rights movement, includes the civil rights movement and is present in science, technology, engineering and mathematics (STEM) equity interventions. For example, Harriet Tubman is broadly recognized for contributions to the abolition of slavery, but her contributions to women's rights, her importance as a feminist and her contributions to anti-racism are under-acknowledged ${ }^{1}$. Similarly, the vision and activities of Black men dominate presentations of the civil rights movement while the contributions of Black women are frequently portrayed as symbolic ${ }^{2}$. To date, STEM diversity initiatives have been successful in promoting inclusion for white women at the expense of scholars of colour ${ }^{3}$, and especially Black women ${ }^{3,4}$. To do the work of justice and equity in ecology and evolution (EE) and beyond, particularly to ensure women of colour are not ignored, we need to adopt attitudes of feminist scientists and scholars who view the world with a more intersectional lens. Too often, Black women are forcibly presented with the choice to acknowledge gender or racial identities, diminishing the power and innovation resultant from integration with detriment to inclusivity.

If we are to be successful in decolonizing racial, structural biases in EE, we must combat barriers to the success of Black women and be intentional to include and promote their contributions. However, we must challenge the Nature Ecology \& Evolution editorial conclusion that "admitting students and recruiting junior researchers and faculty is perhaps where the biggest failing of academic institutions


ignores the many seasoned and young Black women scholars who possess or are currently pursuing EE degrees or careers. Retention, not recruitment, is the primary issue. Black women declare STEM majors at the same rate ${ }^{6}$, but are not retained due to inequities stemming from racialized, social hierarchies that privilege their white counterparts ${ }^{7}$. In all that we do, it is critical to remember and re-state that, "when they [Black women] enter, we all enter" ${ }^{8}$. Making room for the most marginalized among us makes room for us all. Highlighting the work of women of colour in EE with intersecting underrepresented identities gives greater value to our collective work and increases our capacity to overcome systemic biases in inclusion and equity.

Recognition of Black scholars in EE is limited to the accomplishments of a handful of scholars, who are predominantly male. The 23 June editorial cites an article about African-American evolutionary biologists who earned degrees prior to 2000; only one of six included is female. A challenge with such presentations is that visibility is often correlated with standards of success that value high productivity in short time periods ${ }^{9}$, which are measures that frequently omit the contributions of women, and especially women of colour. Women of colour typically carry higher teaching and service loads ${ }^{4}$ that do not enjoy broad professional recognition even when they contribute to increased disciplinary diversity. Coupled with an insidious reflex to trumpet the service work of women of colour, the scientific contributions of Black women are undervalued. In fact, Black women who earned degrees prior to 2000 have conducted impactful research in EE. To list a few examples, this research illustrates the importance of ontogenetic requirements to plant population dynamics ${ }^{10}$, models the combined effects of climate change and land-use history on anthropogenic extinctions of endemics ${ }^{11}$, and pioneers innovative strategies to engage youth in environmental disciplines ${ }^{12}$.

To address this lack of recognition, we need accommodations that recognize the uniqueness of Black women's contributions, broader evaluative metrics and infrastructures to counter financial burdens.

To create an inclusive and valuing discipline, it is critical that we effectively and justly recognize and highlight the work of Black women scholars. This form of representation supports, encourages and empowers women students and early-career scholars in EE. As we see in the current movement for racial justice and ending police brutality, the energy of motivated young activists can yield change. This does not disregard, but validates the past labour of the many Black women who have fought for access, justice, diversity, inclusion and equity in EE. It is past time to move beyond platitudes, virtue signalling and performative allyship to meaningful and impactful change. Good intentions will not institute systematic change. Structural, inclusive and intersectional mechanisms will ensure accountability and improve retention of Black women at all ranks.

Maria N. Miriti (D) ${ }^{1 \times}$, Karen Bailey (D)2, Samniqueka J. Halsey (D) $^{3}$ and Nyeema C. Harris (D) 4

${ }^{1}$ Department of Evolution, Ecology and Organismal Biology, The Ohio State University, Columbus, $\mathrm{OH}$, USA. ${ }^{2}$ University of Colorado Boulder Environmental Studies Program, University of Colorado Boulder, Boulder, CO, USA. ${ }^{3}$ School of Natural Resources, University of Missouri, Columbia, MO, USA. ${ }^{4}$ Department of Ecology and Evolutionary Biology, Applied Wildlife Ecology (AWE) Lab, University of Michigan, Ann Arbor, MI, USA.

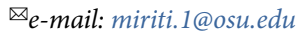

Published online: 27 July 2020

https://doi.org/10.1038/s41559-020-1270-y

References

1. Ramdani, F. Eur. J. Am. Stud. 10, 1-23 (2015).

2. Farmer, A. D. Remaking Black Power (The Univ. of North Carolina Press, 2017).

3. Miriti, M. N. BioScience 70, 237-242 (2020).

4. Corneille, M., Lee, A., Allen, S., Cannady, J. \& Guess, A. Equal. Divers. Incl. 38, 328-348 (2019).

5. Nat. Ecol. Evol. 4, 893-894 (2020).

6. Riegle-Crumb, C., King, B. \& Irizarry, Y. Educ. Res. 48, 133-144 (2019).

7. Muhs, G., Niemann, Y., González, C. \& Harris, A. (eds) Presumed Incompetent: The Intersections of Race and Class for Women in Academia (Univ. Press of Colorado, 2012).

8. Crenshaw, K. Univ. Chic. Leg. Forum 1989, 139-167 (1989).

9. Mountz, A. et al. ACME 14, 1235-1259 (2015).

10. Miriti, M. N. J. Ecol. 94, 973-979 (2006).

11. Benning, T. L., LaPointe, D., Atkinson, C. T. \& Vitousek, P. Proc. Natl Acad. Sci. USA 99, 14246-14249 (2002).

12. Bowser, G., Gretzel, U., Davis, E. \& Brown, M. Sustainability 6, 692-701 (2014).

Competing interests

The authors declare no competing interests. 